\title{
Full-Scale Hardware-in-the-Loop Verification Environment for Heavy-Duty Hybrid Electric Vehicles
}

\author{
Ari Hentunen, Jussi Suomela, Antti Leivo, Matti Liukkonen, Panu Sainio \\ Aalto University, P.O. Box 14300, 00076 AALTO, Finland \\ ari.hentunen@aalto.fi
}

\begin{abstract}
This paper presents an implementation of a versatile full-scale hardware-in-the-loop (HIL) verification environment for testing of heavy-duty hybrid electric vehicles and mobile work machines. The test facility includes a full-scale hybrid system that can be loaded with either an electric motor dynamometer or a programmable chassis dynamometer. Model-based software development tools and rapid control prototyping hardware are used to implement control algorithms and other vehicle controller software as well as to control other test equipment.
\end{abstract}

Hardware-in-the-loop simulation, rapid control prototyping, hybrid electric vehicle, non-road mobile machinery, mobile work machine

\section{Introduction}

The legislation and regulations for the exhaust emissions of the diesel engines used in mobile work machines are tightening remarkably during this decade. The European Union directives 97/86/EC and 2004/26/EC set tight limits for the emissions of carbon monoxide (CO), hydrocarbons (HC), oxides of nitrogen (NOx), and particulates $(\mathrm{PT})[1,2]$. Because of the tightening regulations, more aftertreatment of exhaust gas will be needed, which in turn slows down the engine dynamics, degrades performance, and increases cost. Also fuel price is rising, which increases operation costs of the machinery. In addition, the EU has committed itself to expanding the use of renewable energies by $20 \%$, achieving a $20 \%$ increase in energy efficiency and a $20 \%$ reduction in greenhouse gas emissions by 2020. To tackle all these challenges, the original equipment manufacturers (OEMs) of non-road mobile work machines have shown rising interest to hybridize the drive train.

The EU limits for emissions of variable-speed diesel engines to be installed in non-road mobile machinery according to [2] are illustrated in Fig. 1. The type-approval dates for the engines are one year earlier. The emission limits of the US EPA Tier regulations go in line with the EU limits. As can be seen from the figure, the emis- sion limits are tightening tremendously in near future for engines bigger than $37 \mathrm{~kW}$. For example, the introduction of Stage IIIB will cut the PT emission limit of engines in the power range of $37-75 \mathrm{~kW}$ by $94 \%$, and the introduction of Stage IV will cut the NOx limit of 56-130 kW engines by $88 \%$ and $130-560 \mathrm{~kW}$ engines by $94 \%$, respectively.

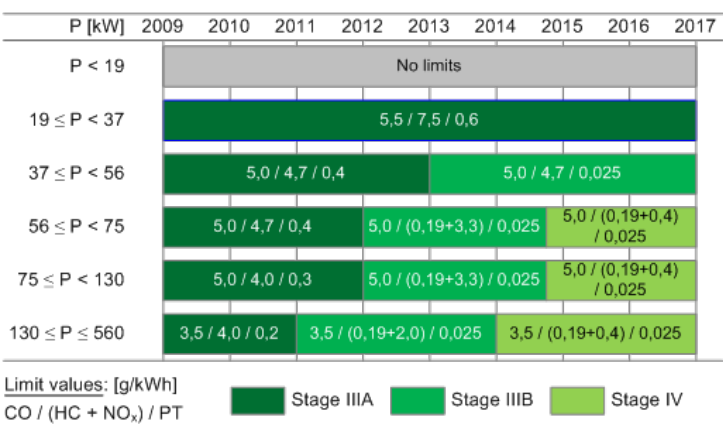

Figure 1: European Union regulations for emission standards for diesel engines other than constant-speed engines to be installed in non-road mobile machinery.

The internal combustion engine (ICE) of a conventional work machine is dimensioned to supply the peak power during the anticipated work 
cycle. Depending on the work machine type and its typical work cycle, the peak power demand might occur e.g. during acceleration, driving uphill with a full load, or driving against the pile when loading the bucket. The average power demand of the work cycle is often close to a half of the peak-power demand. In a hybrid electric driveline, the ICE can be downsized drastically due to the onboard energy storage that can be used during peak-power demand to provide extra power and to store regenerative braking power. With big enough energy storage, e.g. a high power battery, the ICE can be dimensioned to provide only the average power. Thus, with hybridizing the power train, it is often possible to downsize the engine remarkably, and thus, to achieve better fuel economy as well as less emissions. [3] In addition, the emission limits of the downsized engine may be less tight compared to the original limits, because the downsized engine may fit into a smaller power class. As can be seen from Fig. 1, downsizing can be especially beneficial if the engine power can be downsized below $37 \mathrm{~kW}$, since the Stages IIIB and IV do not concern engines that have net power below $37 \mathrm{~kW}$.

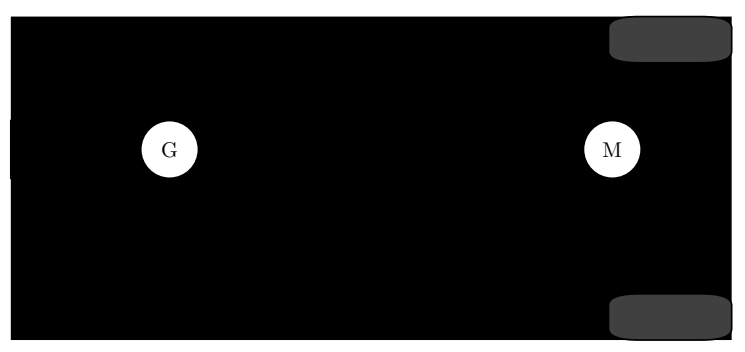

Figure 2: Layout of SHEV.

Hybrid vehicles have at least two energy sources. The primary power source is usually an ICE or a fuel cell (FC) unit, while a battery or an electric double-layer capacitor (EDLC) unit-also commonly known as supercapacitor (SC) or ultracapacitor (UC) unit-acts as a secondary power source. A layout of a generic series hybrid electric vehicle (SHEV) driveline is shown in Fig. 2. In SHEVs, all traction power is transferred in electrical form. The ICE is only a source of electrical power. Because the vehicle speed is totally decoupled from the engine speed, the ICE can be controlled to trace the optimal efficiency or lowest emissions, or to optimize some other criteria. To avoid resistive losses, fairly high DC link voltage is usually chosen. If the battery is coupled directly to the DC link, then the battery voltage determines also the DC link voltage. However, the DC-DC converter is often used to decouple the ES from the DC link. Then it is possible to control directly the ES current. Therefore, the use of a DC-DC converter also allows more sophisticated power management strategies.

The advent of electric transmission poses also new challenges for OEMs of mobile work machines. The OEMs need to develop new traction control algorithms as well as power management strategies. Electrification offers more performance and degrees of freedom in the de- sign and optimization, but the control strategies become easily quite complex to implement. It must also be kept in mind that many OEMs do not have strong experience with electric traction drives and other power electronic (PE) and high power electrical equipment.

Testing of the control software is not a straightforward task. The electric motors (EMs) rotate with speeds up to $15000 \mathrm{rpm}$ with only a millisecond order of response times for full torque. There may also occur failures e.g. in contactor control that may result in very high inrush currents and possibly arcing and hardware failures. Therefore, it is a good practice to first simulate the control algorithms against a plant model, and then validate and verify the control software in a laboratory environment. $[4,5]$

Model-based software development (MBSD) and rapid control prototyping ( $\mathrm{RCP}$ ) hardware and software are widely used in automotive industry [6-14]. With the increasing amount of software in the mobile work machines, the MBSD and RCP are getting more attention also in mobile work machine industry. With these tools it is straightforward to make early designs, validate the controller against plant models, and implement the algorithms in a real RCP electronic controller unit (ECU) by utilizing automatic code generation (ACG). Furthermore, the controller model can later be customized for the real production ECU, which shortens the gap between the prototype and the final product.

The paper is organized as follows. The HIL verification environment is described in detail in section 2. Experimental results of HIL simulation and efficiency measurements are presented in section 3. Section 4 concludes the paper.

\section{HIL Verification Environment}

\subsection{Objectives}

The main objective is to make HIL simulations with full-scale power hardware for different SHEV topologies. With full-scale power hardware, it is also possible to get insight into all aspects of the electrification of mobile work machines, including e.g.

- control algorithm development and diagnostics

- real interface electronics and time delays in command values, and communication through e.g. controller area network (CAN)

- cabling, electromagnetic interference (EMI), and safety issues with devices up to $1000 \mathrm{~V}$

- noise vibration and harshness

- physical size and weight

- thermal behavior and management 
The second objective is to validate the plant models of the simulation platform that have been made in recent years to simulate hybridization configurations for different kinds of mobile work machines. This objective is actually a very important one, because good consistency between the model and the real plant yields to accurate and reliable simulation results, and on the other hand, poor consistency gives unreliable information that is more or less useless.

In order to achieve good accuracy for the fuel consumption and to be able to develop control algorithms that work also in real vehicle-not just in a simulator-detailed information about the efficiency of the devices in the hybrid drive train is needed. Unfortunately, such information is rarely available from the subsystem suppliers. It is common that the manufacturers give the efficiency only in the nominal point. Therefore, one important objective is the ability to measure the efficiency maps of EMs, hydraulic pumps and motors, power electronic converters (PECs), etc. That information can later be used in the plant models as well as in the control algorithms.

\subsection{Overview}

A full-scale power HIL verification environment has been implemented in the university facilities to research and demonstrate the electrification of mobile work machines. The layout of the power HIL hardware is shown in Fig. 3. The components are mostly off-the-shelf products that are available on the market. The nominal dc link voltage is $650 \mathrm{~V}$, which is a common voltage rating for HEV buses and work machines.

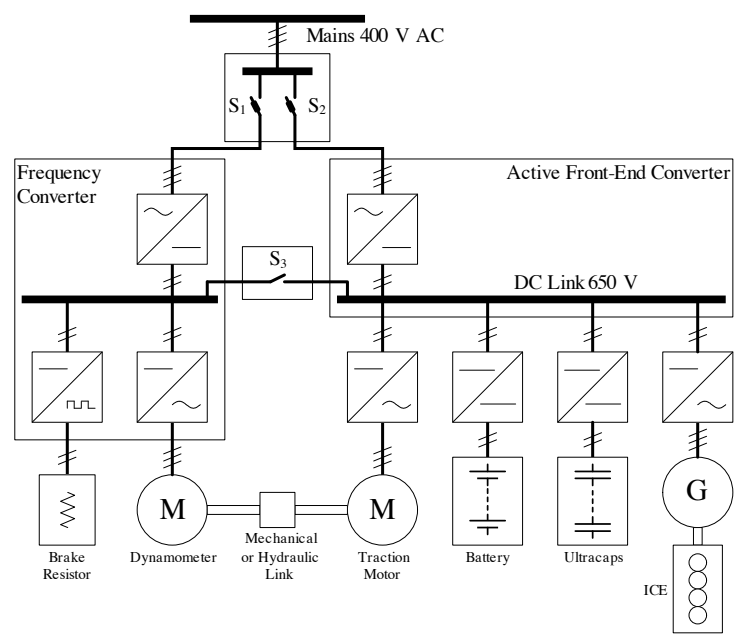

Figure 3: Power hardware layout of the HIL verification environment.

There are two switches in the system $\left(S_{1}\right.$ and $\left.S_{2}\right)$ that connect the ac-dc converters to the mains, and a third switch $S_{3}$ that interconnects the dc link to the intermediate dc link of the frequency converter. In this paper, switches $S_{1}$ and $S_{2}$ are assumed to be closed and $S_{3}$ to be open unless otherwise stated. The right-hand side from the switch $S_{3}$ is the HEV system under test (SUT), and the left-hand side constitutes an EM dynamometer for the traction motor. The frequency converter incorporates a brake chopper, which is connected to a brake resistor to allow regenerative braking when the switch $S_{3}$ is open.

The power ratings of the hardware are shown in Table 1 . The power rating of the UC unit and its dc-dc converter are for the nominal voltage, which is also very close the maximum voltage, and thus, can be regarded as the power when the UCs are fully charged. When the UCs are being discharged, the available power decreases linearly with the voltage. Thus, at the half of the nominal voltage the continuous power is half of the power that is shown in Table 1 . For the battery, the nominal and maximum power rating that are shown in the table are for discharge operation. Charging power must be remarkably lower.

Table 1: Continuous power $P$ and maximum power $P_{\max }$ of the subsystems

\begin{tabular}{clrr}
\hline System & Hardware & $\begin{array}{c}P \\
{[\mathrm{~kW}]}\end{array}$ & $\begin{array}{r}P_{\max } \\
{[\mathrm{kW}]}\end{array}$ \\
\hline \multirow{5}{*}{ HEV } & ICE & 92 & 120 \\
& Generator & 120 & 130 \\
& Gen. inverter & 160 & 172 \\
& Motor & 67 & 150 \\
& Motor inverter & 120 & 200 \\
& Battery & 72 & 144 \\
& Battery dc-dc & 43 & 72 \\
& Ultracap. & 59 & 234 \\
& Ultracap. dc-dc & 47 & 78 \\
\hline \multirow{2}{*}{ DC power } & AFE & 310 & 340 \\
\hline \multirow{5}{*}{ Dynamo } & Load motor & 67 & 150 \\
& Load inverter & 120 & 200 \\
& Brake resistor & 20 & 100 \\
\hline
\end{tabular}

\subsection{HEV System}

As can be seen from Fig.3, the hybrid system resembles the SHEV topology that has dc-dc converters between energy storages and the common dc link. The HEV system consists of

- ICE-generator set (gen-set) with a generator inverter

- ultracapacitor module with a bidirectional $\mathrm{dc}-\mathrm{dc}$ converter

- battery with a bidirectional dc-dc converter

- traction motor and inverter

The system includes also an active front-end (AFE) that can be used to provide dc power if the gen-set and the battery are not used in the test setup. AFE actually acts like a battery in the dc link, because it regulates the dc link voltage to a desired value, and thus, provides the difference between the generated power and the consumed power. 


\subsubsection{Gen-Set Unit}

The diesel engine is AGCO SISU POWER 49 DTAG [15]. The continuous power rating of the SG 115 gen-set is $92 \mathrm{~kW}$ at $1500 \mathrm{rpm}$ and limited power rating is $102 \mathrm{~kW}$ at $1500 \mathrm{rpm}$. However, the original generator has been replaced with a permanent magnet (PM) axial-flux generator manufactured by AXCO-Motors [16]. The generator has eight poles and its apparent power rating is $125 \mathrm{kVA}$ and electric power rating is $120 \mathrm{~kW}$ at $2000 \mathrm{rpm}$. The generator is coupled directly to the crankshaft of the engine and it is liquid-cooled.

Together the ICE and the generator constitute a variable-speed diesel-generator (VSDG) set that has a nominal speed of $2000 \mathrm{rpm}$, nominal apparent power of $125 \mathrm{kVA}$, and nominal electric power of $120 \mathrm{~kW}$, and nominal electrical angular frequency of $133 \mathrm{rad} / \mathrm{s}$. The ac from the generator is converter to regulated dc voltage with a frequency converter that is operating in dc link voltage control mode. The input ac is not connected, but the dc link of the frequency converter is connected to the common dc link.

The manufacturer of the frequency converter is $\mathrm{ABB}$ and the type code of the converter is ACSM1-04LS-260A-4+K457 [17]. The converter is liquid-cooled, and it is controlled via CAN bus. The continuous power rating is $160 \mathrm{~kW}$. The converter incorporates also a brake chopper, and a brake resistor will be installed in it later.

\subsubsection{Electric Traction Drive}

The electric motor and the inverter are from Siemens electric drive system ELFA [18]. The motor type is 1PV5135-4WS28 and the inverter type is G650 D440/170/170 M7-1. The motor is an induction motor with four poles and maximum speed of $10000 \mathrm{rpm}$. The nominal torque is achieved with $124 \mathrm{~A}$ current and is $160 \mathrm{Nm}$ at $4000 \mathrm{rpm}$. The maximum torque with $300 \mathrm{~A}$ current is $430 \mathrm{Nm}$ at $2500 \mathrm{rpm}$. With a little lower maximum current of $250 \mathrm{~A}$ that yields to $360 \mathrm{Nm}$ torque the constant torque region can be extended to $4000 \mathrm{rpm}$, and thus the maximum power is $150 \mathrm{~kW}$.

The inverter actually includes two three-phase insulated gate bipolar transistor (IGBT) inverters and two brake choppers. However, only one inverter is in use at the moment. The nominal $\mathrm{dc}$ link voltage is $650 \mathrm{~V}$, output voltage $440 \mathrm{~V}$ ac, and output current $170 \mathrm{~A}$, respectively. The maximum output current is $300 \mathrm{~A}$. Both the motor and the inverter are liquid cooled.

\subsubsection{Ultracapacitor}

The nominal voltage of the ultracapacitor unit was considered to be around $400 \mathrm{~V}$. That is firstly because the UC voltage must be lower than the dc link voltage. $400 \mathrm{~V}$ unit can also store enough energy so that it can be used as a peak-power buffer for various kinds of work machines. The volume of the $400 \mathrm{~V}$ unit is also still small enough to be installed in the vehicle.

An HTM power series 390v module with a type code BMOD0018 P390 was selected as the UC unit. It is a complete package with all the electrical connections, voltage balancing, thermal monitoring, cooling, and cooling fans assembled inside the enclosure. The capacitance is $17.8 \mathrm{~F}$ and the nominal voltage is $390 \mathrm{~V}$. The unit comprises 146 series connected $2.7 \mathrm{~V}$ cells with 150 A nominal and 900 A maximum current ratings, respectively. HTM power series $390 \mathrm{v}$ is not in production anymore.

\subsubsection{Battery}

Lithium-polymer battery consists of 98 cell that are connected in series. Battery manufacturer is Kokam, and the cell type is SLPB $100216216 \mathrm{H}$, which is a 40 Ah cell [19]. The nominal voltage is $3.7 \mathrm{~V}$, minimum voltage $2.7 \mathrm{~V}$, and maximum voltage $4.2 \mathrm{~V}$, respectively. Maximum charge current is $80 \mathrm{~A}$, nominal discharge current $200 \mathrm{~A}$, and maximum discharge current for $10 \mathrm{~s}$ is $400 \mathrm{~A}$, respectively.

Battery cells are pre-assembled in modules that have seven cells connected in series and include voltage measurements for each cell and four temperature measurements, which are located between every other two adjacent cells. A variablespeed cooling fan has been added in front panel of each module, and vent holes have been made in sides of the modules. The battery comprises 14 modules that are connected in series. The nominal voltage of a module is $25.9 \mathrm{~V}$, and thus, the nominal voltage of the battery is $362 \mathrm{~V}$. One extra battery module is also available in the laboratory to be tested separately.

The battery management system (BMS) is manufactured by Elithion [20]. It consists of a BMS controller and 14 cell boards, one for each battery module. Cell boards are located inside battery modules. The extra battery module has its own BMS.

\subsubsection{DC-DC converter}

The bidirectional three-phase boost converter topology is shown in Fig. 4. The converter is manufactured by MSc Electronics [21] and its model is 200DCDC750A2SN. The converter utilizes multi-phase interleaving, which reduces current ripple. The nominal ES side current of the converter is $120 \mathrm{~A}$ and the maximum current is $200 \mathrm{~A}$.

The converter is controlled with a current reference. Also hardwired tunable minimum and maximum voltage limits for the input and the output are incorporated into the control system to prevent over- and undervoltages in the system. The voltage of the energy storage (ES) needs to be lower than the dc link voltage. If the dc link voltage decreases and goes below the ES voltage, the diodes in the power stage begin to conduct current from the ES to the dc link, and thus, the voltages stay equal until the dc link voltage starts 


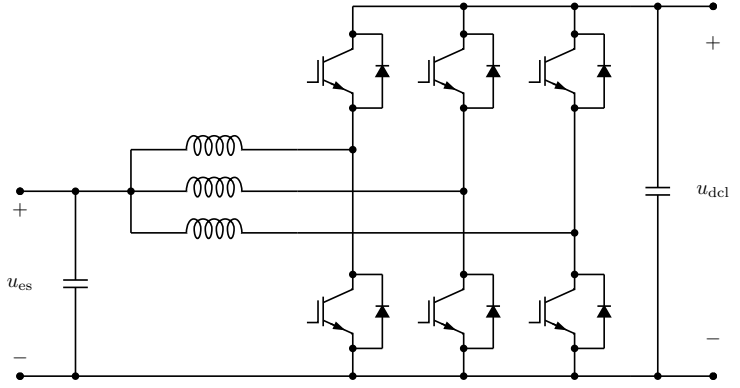

Figure 4: Bidirectional three-phase boost converter.

to rise. The minimum current of the converter is $20 \mathrm{~A}$.

\subsection{DC power supply}

Vacon Active Front-End (AFE) with NXA_04605 input module [22] is used as a dc power supply. The nominal ac current is $460 \mathrm{~A}$ and the continuous dc output power rating is $310 \mathrm{~kW}$. AFE includes a three-phase IGBT bridge, an LCL line filter, and a pre-charge circuit. AFE regulates the dc link voltage the desired setpoint. The recommended output voltage range is about $600-700 \mathrm{~V}$ dc for $400 \mathrm{~V}$ ac mains voltage. The input power factor can be set to unity, thus no reactive power is consumed.

AFE can be controlled and monitored via CAN bus or from the panel. It is possible to set a positive and a negative current limit. However, if the consumed power is more than the current limit allows, the dc link voltage decreases, and at a certain point, the diodes of the IGBT bridge begin to conduct and keep the dc link voltage at rectified mains voltage of $540 \mathrm{~V}$.

\subsection{Load dynamometer}

An electric motor dynamometer is used to load the traction motor. The motor manufacturer and model are the same as the traction motor, which is attached to the test bench (subsection 2.3.2). However, the original speed sensor has been replaced with SICK CKS36 Encoder, which has resolution of $1024 \mathrm{bit} / \mathrm{rev}$. The dynamometer can be used to test also other traction motors by replacing the equipment under test (EUT) with another EM.

Vacon NXP frequency converter with an inverter unit INU_0300 5 is used to control the EM. Frequency converter can be controlled and monitored via CAN bus. The motor can be controlled either with a torque reference with a speed limit or with a speed reference with a torque limit.

When the dynamometer is braking the traction motor, and hence, acting as a generator, the braking power is dumped to the brake resistor through the brake chopper. The dc links of the frequency converter and AFE can also be interconnected by closing the switch $S_{3}$. Then, the generated power flows back to the dc link and can be used e.g. to provide power to the traction motor. If the tractive power is provided by the gen-set or battery, then AFE feeds the generated power back to the mains.

\subsection{Mechanics}

The mechanical environment is built on high insulation rubber floor using $\mathrm{T}$-slot beams with weight of $500 \mathrm{~kg}$ each. Also all fastening components have been overdimensioned by purpose to have a very rigid mounting and to avoid the need for unnecessary flexible couplings. The couplings used are jaw-type couplings, thus allowing axial plug-in, good dynamics, vibration reduction, and failsafe behavior. In case of overload, they do allow some torsional flexibility.

\subsection{Measurement Equipment}

The mechanical torque and speed of the traction motor are measured with a KTR Dataflex $42 / 1000$ transducer. The transducer is installed in the mechanical link in the coupling between the motors.

Norma D6100 power analyzer has been used to measure electrical power and efficiency of the EMs, PECs, and other EUT. Measurement data are transferred through RS232 link to the host computer.

A new Hioki 3390 power analyzer with motor testing option and D/A output option has been recently acquired to the laboratory. It has four channels and the motor testing option, which calculates the mechanical power from the measured torque and speed information. Currents are sensed with ac/dc clamp on CT 9278 current clamps, which have a maximum continuous input current of $350 \mathrm{~A}$ for a bandwidth of $19 \mathrm{kHz}$, $200 \mathrm{~A}$ for $40 \mathrm{kHz}$, and $100 \mathrm{~A}$ for $100 \mathrm{kHz}$, respectively.

Ultracapacitor voltage is measured with LEM AV100-750 transducer and current with LEM LA 305-S transducer.

\subsection{Other Equipment}

A programmable chassis dynamometer for two wheels and a cold/warm chamber, which has a temperature range of $-50 \ldots+50{ }^{\circ} \mathrm{C}$, are available in the laboratory facilities. The size of the chamber is big enough to drive a van inside. The programmable chassis dynamometer is located next to the dc power supply and energy storages.

\subsection{Cooling Circuit}

A common rail liquid cooling circuit with six independent branches that are controlled with electrically operated valves is used to provide proper cooling for liquid-cooled subsystems. An electric pump from EMP is used to control the flow in the common rail, and electrical valves are used to open and close branches. Flow, pressure, and temperature data from each branch are measured and sent to the ECU. 
From the cold chamber circulation there is also a separate $-20^{\circ} \mathrm{C}$ circulation of water-glycol mixture available, if extensive cooling circulation is needed.

\subsection{Control System}

Almost all laboratory equipment is controlled with a dSPACE MicroAutoBox (MABX) DS1401/1505/1507 RCP ECU. It has four CAN buses and lot's of analog and digital I/O. The voltage level of the digital $\mathrm{I} / \mathrm{O}$ is $5 \mathrm{~V}$, analog inputs $5 \mathrm{~V}$, and analog outputs $4.5 \mathrm{~V}$, respectively. However, because voltage levels of some devices is exceed those, some additional analog and digital $\mathrm{I} / \mathrm{O}$ has been implemented using Beckhoff's industrial automation I/O modules. Beckhoff's I/O modules communicate with MABX via CAN bus.

MBSD is utilized to produce code for the RCP ECU. Models are made with MATLAB/Simulink/Stateflow. Also Real-Time Workshop and dSPACE RTI blockset are needed to generate $\mathrm{C}$ code from the Simulink model. The compiled code is then uploaded into the MABX, after which the controller starts executing the real-time program. The ECU is connected to the host computer via high speed link. All measurements as well as other signals can be monitored online from the host computer through dSPACE ControlDesk. A graphical user interface (GUI) has been made for every device that is controlled with the ECU. It is also possible to tune online e.g. the constant parameters and the gains of the original model. This makes it easy to implement manual controls of the laboratory equipment directly from the host computer.

\subsection{Simulation Platform}

A flexible simulation platform has been created that includes a library of easily parametrizable plant models of HEV systems, e.g. EMs, inverters, dc-dc converters, battery, ultracaps, gears, ICE, etc. With the simulation platform it is easy and fast to make early simulations of different kind of hybridization configurations for mobile work machines and to develop and evaluate control strategies for them. Simulation time-step is $1 \mathrm{~ms}$. Backward functional modeling from the imposed load cycle is utilized in simulating the HEV system. The load cycle can be a mechanical load for EMs or an electrical load that is formed e.g. from the measured traction power data of a conventional machine.

The accuracy of the models has been defined to resemble large signal behavior and to neglect fast transients and all switching frequency characteristics of PE converters and EMs. This is because simulated driving cycles are long and detailed models that include switching behavior take very long time to execute and need detailed information about the plant.

\section{Experimental Results}

\subsection{Efficiency Measurements}

The efficiency maps of the traction motor, inverter, dc-dc converter, and ultracapacitor unit have been measured with Norma D6100 power analyzer. Mechanical torque and speed measurements from torque transducer were used to calculate mechanical power of the EM. During the measurements of the traction motor and inverter, the switch $\mathrm{S}$ from Fig. 3 was set to closedposition and $S_{1}$ to open-position, respectively. This allows the braking power of the dynamometer to be used to provide power for the traction motor. Thus, only losses are taken from the mains.

The efficiency map of the traction motor and inverter were done by controlling the dynamometer with a speed reference and the EUT with a torque reference. The speed range was measured at speed intervals of $200 \mathrm{rpm}$. In each speed setpoint, torque range was measured at torque intervals of $20 \mathrm{Nm}$. The measurements were made after a steady-state had been achieved. The power analyzer can calculate the electrical power of a three-phase symmetrical load from two line-toline voltages and two phase currents. Therefore, it was possible to measure the input and output power of the inverter simultaneously by measuring the dc link voltage and current, and two lineto-line output voltages and two phase currents. With the mechanical torque and speed measurements, both the EM and the inverter efficiency maps were achieved. In the simulation models it is enough to have a combined map for the traction motor and inverter. The measured combined efficiency map is shown in Fig. 5. It can be seen that the best efficiency can be achieved with speeds beyond the nominal point of the motor.

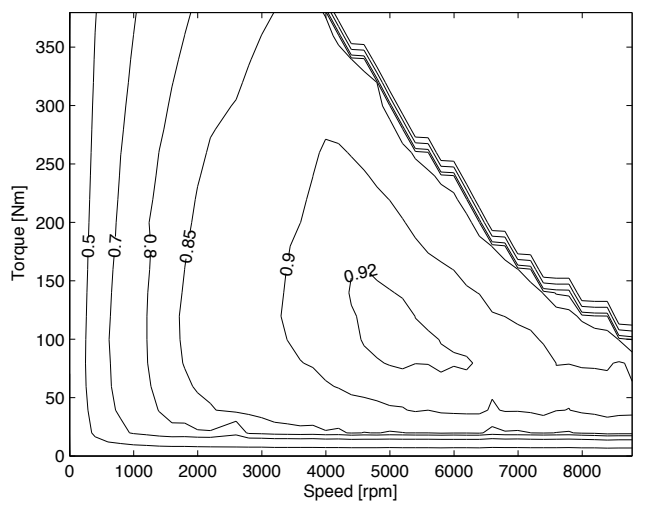

Figure 5: Combined measured efficiency map of Siemens ELFA 1PV5135-4WS28 traction motor and G650 D440/170/170 M7-1 inverter. 


\subsection{HIL Simulation of SHEV Load Sharing Algorithm}

Simulation model validation is demonstrated with a HIL simulation, where an UC stack is used to provide peak power during short power peaks. Thus, the primary power source-e.g. an ICE or a fuel cell - dynamics need not be as fast, and the primary power source can be downsized. In this HIL simulation, the dc power supply was used to emulate the primary power source. The load power was made with the EM dynamometer. The control stategy, plant models, and experimental results are described in more detail in [23].

Two modeling principles for the ultracapacitor were used in the simulation: constant capacitance (constant C) with equivalent series resistance (ESR), and variable capacitance (variable C) with ESR. In the constant $\mathrm{C}$ model, the nominal capacitance value was used. In the variable $\mathrm{C}$ model, the capacitance has been calculated from the constant current measurements, and a capacitance mapping has been defined based on the calculations, i.e. the capacitance depends on the voltage and current.

Validation measurements are shown in Fig. 6. It can be seen that the simulated and measured currents and voltages match quite well. However, there are some abnormalilities especially in the currents. These are due to several reasons, one being the dc-dc converter's minimum current of $20 \mathrm{~A}$, which causes differences in near zero current, even though that functionality is modeled in the plant model. Another cause for differences is that the exact behavior of the dc power supply's voltage regulator is hard to model. However, the mean error is only $-0.32 \mathrm{~A}$ and the rms error 5.7 A. For the UC voltages, the variable $\mathrm{C}$ model gives more accurate results with mean error of $1.7 \mathrm{~V}$ and rms error $3.0 \mathrm{~V}$.

\section{Conclusion}

A versatile full-scale HIL verification environment for HIL simulations of heavy-duty hybrid electric vehicles and work machines was presented. The environment includes a full-scale hybrid electric power system with a gen-set, a battery, an ultracapacitor unit, and a traction drive. It also includes an EM dynamometer, a high-power dc power supply, a closed-loop cooling circulation, and a versatile and powerful control system with automatic code generation and RCP hardware and software.

The HIL verification environment is located at university facilities and it can be used for research and education purposes as well as for making case-study HIL simulations for work machine manufacturers. The test facility has been used e.g. to measure the efficiencies of PECs, EMs, and hydraulic pumps and motors, to characterize devices and validate plant models, to make experimental HIL simulations to verify and validate HEV control algorithms, to provide load cycles for energy storage testing, and to provide high and controllable electric power for various other research equipment.

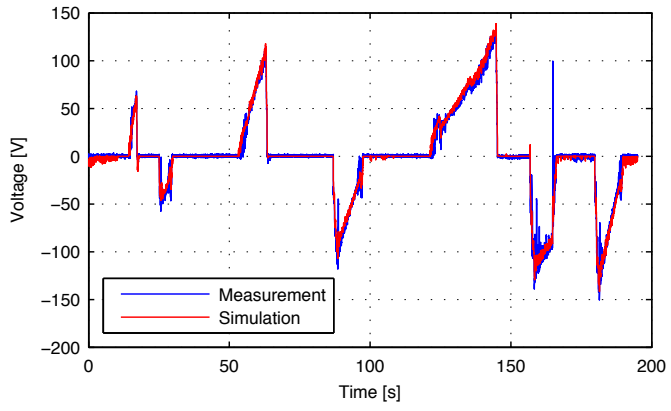

(a) DC-DC converter current.

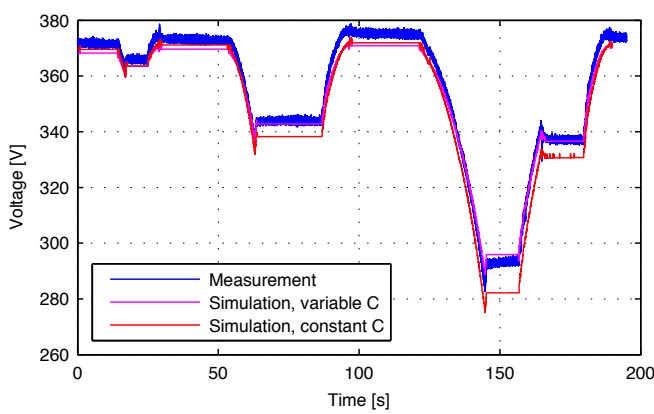

(b) Ultracapacitor voltage.

Figure 6: Comparison of measured and simulated ultracapacitor voltage.

\section{Acknowledgments}

This study has been carried in HybDrive and HybLab projects funded by the Finnish Funding Agency for Technology and Innovations (Tekes) and Multidisciplinary Institute of Digitalization and Energy (MIDE) of Aalto University, respectively.

\section{References}

[1] "Directive 97/68/EC of the European Parliament and of the Council of 16 December 1997 on the approximation of the laws of the Member States relating to measures against the emission of gaseous and particulate pollutants from the internal combustion engines to be installed in non-road mobile machinery," Journal of the European Union L 59 of February 1998, page 1 et seq. [Online]. Available: http://ec.europa.eu/enterprise/sectors/ mechanical/non-road-mobile-machinery

[2] "Directive 2004/26/EC of the European Parliament and of the Council of 21 April 2004 amending Directive $97 / 68 / \mathrm{EC}$ on the approximation of the laws of the Member States relating to measures against the emission of gaseous and particulate pollutants from internal combustion 
engines to be installed in non-road mobile machinery," Journal of the European Union L 146 of April 2004, page 1 et seq. [Online]. Available: http://ec.europa.eu/enterprise/sectors/ mechanical/non-road-mobile-machinery

[3] T. Lehmuspelto, M. Heiska, A. Leivo, and A. Hentunen, "Hybridization of a mobile work machine," World Electric Vehicle Journal, vol. 3, 2009. [Online]. Available: http://www. evs24.org/wevajournal/

[4] M. J. Marcel, T. A. Haskew, and K. A. Williams, "Test facility for a hybrid fuel cell electric vehicle," Proc. IEEE, pp. 734-739, Mar. 2007.

[5] R. M. Schupbach and J. C. Balda, "A versatile laboratory test bench for developing powertrains of electric vehicles," in Proc. IEEE Vehicular Technology Conference 2002 Fall, vol. 3, Vancouver, Canada, Sep. 2002, pp. 1666-1670.

[6] J. Weber, Automotive Development Processes: Processes for Succesful Customer Oriented Vehicle Development. Berlin, Germany: Springer, 2009.

[7] S. C. Nagaraj and B. Detrick, "HIL and RCP tools for embedded controller development in hybrid vehicles," Dearborn, MI, Sep. 2009, pp. 896-902.

[8] A. Wagener, P. Seger, C. Koerner, and H. Kabza, "Simulation-based automatic code-generation for ECUs in distributed control systems, applied in a testbed for a hybrid vehicle drivetrain," vol. 2, Cholula, Puebla, Mexico, Dec. 2000, pp. 643-648.

[9] A. Leivo, J. Suomela, and A. Hentunen, "Model reusability and cooperation in model based HEV control system development," Stavanger, Norway, May 2009.

[10] C. Lin and L. Zhang, "Hardware-in-the-loop simulations and its application in electric vehicle development," Harbin, China, Nov. 2008.

[11] H. Hu, G. Xu, and Y. Zhu, "Hardware-in-theloop simulation of electric vehicle powertrain system," in Proc. Power and Energy Engineering Conference, Wuhan, China, Mar. 2009.

[12] A. Bouscayrol, W. Lhomme, P. Delarue, B. Lemaire-Semail, and S. Aksas, "Hardwarein-the-loop simulation of electric vehicle traction systems using energetic macroscopic representation," in Proc. IEEE 32nd Annual Conference on Industrial Electronics (IECON 2006), Paris, France, Nov. 2006, pp. 5319-5324.

[13] A. Bouscayrol, "Different types of hardware-inthe-loop simulation for electric drives," Cambridge, UK, Jun. 2008, pp. 2146-2151.
[14] Y. Cheng, J. V. Mierlo, P. Lataire, and G. Maggetto, "Test bench of hybrid electric vehicle with the super capacitor based energy storage," Vigo, Spain, Nov. 2007, pp. 147-152.

[15] AGCO Sisu Power homepage. [Online]. Available: http://www.agcosisupower.com/

[16] AXCO-Motors homepage. [Online]. Available: http://www.axcomotors.com/

[17] ABB homepage. [Online]. Available: http: //www.abb.com/

[18] Siemens electric drive system ELFA. [Online]. Available: http://www.siemens.com/elfa/

[19] Kokam homepage. [Online]. Available: http: //www.kokam.com/

[20] Elithion homepage. [Online]. Available: http: //www.elithion.com/

[21] MSc Electronics homepage. [Online]. Available: http://www.mscelectronics.fi/

[22] Vacon homepage. [Online]. Available: http: //www.vacon.com/

[23] M. Liukkonen, A. Hentunen, and J. Suomela, "Validation of quasi-static series hybrid electric vehicle model," Lille, France, Sep. 2010. (in press).

\section{Authors}

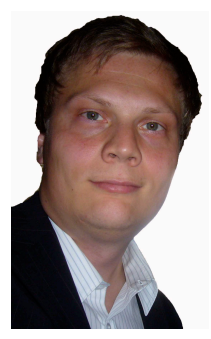

\begin{abstract}
Ari Hentunen
Ari Hentunen received his M.Sc. (Tech.) degree in electrical engineering from the Helsinki University of Technology, Finland, in 2005. Currently he is working as a researcher at the Aalto University, Department of Electrical Engineering. His main research interests are in the field of hybrid electric work machines and modeling of lithiumion batteries.
\end{abstract}



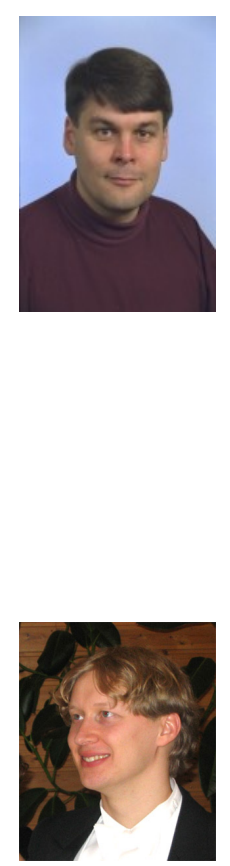

Antti Leivo Antti Leivo received his M.Sc. degree in automation and systems technology from the Helsinki University of Technology, Finland, in 2005. He has been working since 2005 as a researcher at the Helsinki University of Technology. His main research projects are in the field of model based software development of hybrid electric work machines.

Matti Liukkonen Matti Liukkonen (S09) was born on July 19, 1983. He received the M.Sc. (Tech.) degree in electrical engineering from the Helsinki University of Technology (HUT), Espoo, Finland, in 2009. His major fields of studies are in power electronics, hybrid power trains and electric drives.

Panu Sainio Panu Sainio obtained M.Sc in 1997, and Lic.Sc in 2006. He has been participating in a number of national and international projects of vehicle engineering and testing. His primary research interests are tire-road contact and heavy hybrid vehicles. 